SUPPORTING INFORMATION

\title{
Exposure to environmental pollutants and their association with biomarkers of aging: a multipollutant approach
}

Annette Vriens 1; Tim S. Nawrot 1,2; Bram G. Janssen 1; Willy Baeyens 3; Liesbeth Bruckers 4; Adrian Covaci 5; Sam De Craemer 3; Stefaan De Henauw 6; Elly Den Hond 7; Ilse Loots 8; Vera Nelen 7; Thomas Schettgen 9; Greet Schoeters 10; Dries S. Martens 1; Michelle Plusquin 1*

PAges: 14

SUPPLEMENTAL TABLES: 7

SUPPLEMENTAL FIGURES: 6 
Table S1: Overview of pollutants not included in the analyses, because of the high proportion undetectable measurements $(n=175)$

\begin{tabular}{lll}
\hline $\begin{array}{l}\text { Biomarker of } \\
\text { exposure }\end{array}$ & $\begin{array}{l}\text { Method limit of } \\
\text { detection }(\mathbf{M L D})\end{array}$ & Proportion below ML \\
\hline Chromium & LOD $=0.199 \mu \mathrm{g} / \mathrm{l}$ & $85.1 \%$ \\
Lindane $(\mathrm{\gamma}-\mathrm{HCH})$ & $\mathrm{LOQ}=5 \mathrm{ng} / \mathrm{L}$ & $96.0 \%$ \\
BDE-28 & $\mathrm{LOQ}=2 \mathrm{ng} / \mathrm{L}$ & $98.9 \%$ \\
$\mathrm{BDE}-47$ & $\mathrm{LOQ}=2 \mathrm{ng} / \mathrm{L}$ & $34.9 \%$ \\
$\mathrm{BDE}-100$ & $\mathrm{LOQ}=2 \mathrm{ng} / \mathrm{L}$ & $68.6 \%$ \\
$\mathrm{BDE}-99$ & $\mathrm{LOQ}=2 \mathrm{ng} / \mathrm{L}$ & $72.0 \%$ \\
$\mathrm{BDE}-154$ & $\mathrm{LOQ}=2 \mathrm{ng} / \mathrm{L}$ & $98.3 \%$ \\
$\mathrm{BDE}-183$ & $\mathrm{LOQ}=2 \mathrm{ng} / \mathrm{L}$ & $100 \%$ \\
$\mathrm{PFBS}$ & $\mathrm{LOQ}=0.2 \mu \mathrm{g} / \mathrm{L}$ & $94.9 \%$ \\
\hline
\end{tabular}


Table S2: Health aspects of the study population

\begin{tabular}{|c|c|}
\hline Health parameters & Number (\%) \\
\hline \multicolumn{2}{|l|}{ How would you consider your overall health ${ }^{a}$} \\
\hline Very good & $26(15.03 \%)$ \\
\hline Good & $92(53.18 \%)$ \\
\hline Normal & $51(29.48 \%)$ \\
\hline Bad & $4(2.31 \%)$ \\
\hline Very bad & 0 \\
\hline \multicolumn{2}{|l|}{ Hypertension } \\
\hline Elevated blood pressure ${ }^{b}$ & $62(35.43 \%)$ \\
\hline Anti-hypertensive medication & $50(28.57 \%)$ \\
\hline Elevated blood pressure or medication use & $90(51.43 \%)$ \\
\hline \multicolumn{2}{|l|}{ Dyslipidaemia } \\
\hline Reduced HDL levels ${ }^{\mathrm{c}}$ & $27(15.43 \%)$ \\
\hline Elevated triglyceride levels ${ }^{d}$ & $52(29.71 \%)$ \\
\hline $\begin{array}{l}\text { Medication for hypercholesterolemia or } \\
\text { dyslipidaemia }\end{array}$ & $36(20.57 \%)$ \\
\hline \multicolumn{2}{|l|}{ Hyperglycaemia / type 2 diabetes } \\
\hline Elevated $\mathrm{Hb} 1 \mathrm{Ac}$ e & $2(1.50 \%)$ \\
\hline Metformin medication use & $4(2.29 \%)$ \\
\hline \multicolumn{2}{|l|}{ Weight changes in the last 5 years ${ }^{f}$} \\
\hline No & $92(61.74 \%)$ \\
\hline Gained weight & $42(28.19 \%)$ \\
\hline Lost weight & $15(10.07 \%)$ \\
\hline \multicolumn{2}{|c|}{$\begin{array}{l}\text { a: } n=173 \text {, self-reported; b: elevated blood pressure was defined as systolic blooc } \\
\text { pressure } \geq 140 \mathrm{mmHg} \text { or diastolic blood pressure } \geq 90 \mathrm{mmHg} \text {; } \text { : reduced } \mathrm{HDL} \\
\text { levels were defined as } \mathrm{HDL}<40 \mathrm{mg} / \mathrm{dl} \text { for men or } \mathrm{HDL}<45 \mathrm{mg} / \mathrm{dl} \text { for women; } \\
\text { d: elevated triglycerides were defined as triglyceride }>200 \mathrm{mg} / \mathrm{dl} \text {; e: } \mathrm{n}=133 \text {, } \\
\text { elevated } \mathrm{Hb} 1 \mathrm{Ac} \text { levels was defined as } \mathrm{Hb} 1 \mathrm{Ac} \geq 6.5 \% ; \mathrm{f}: \mathrm{n}=149 \text {, self-reported. }\end{array}$} \\
\hline
\end{tabular}


Table S3: Association of biomarkers of aging and important covariables

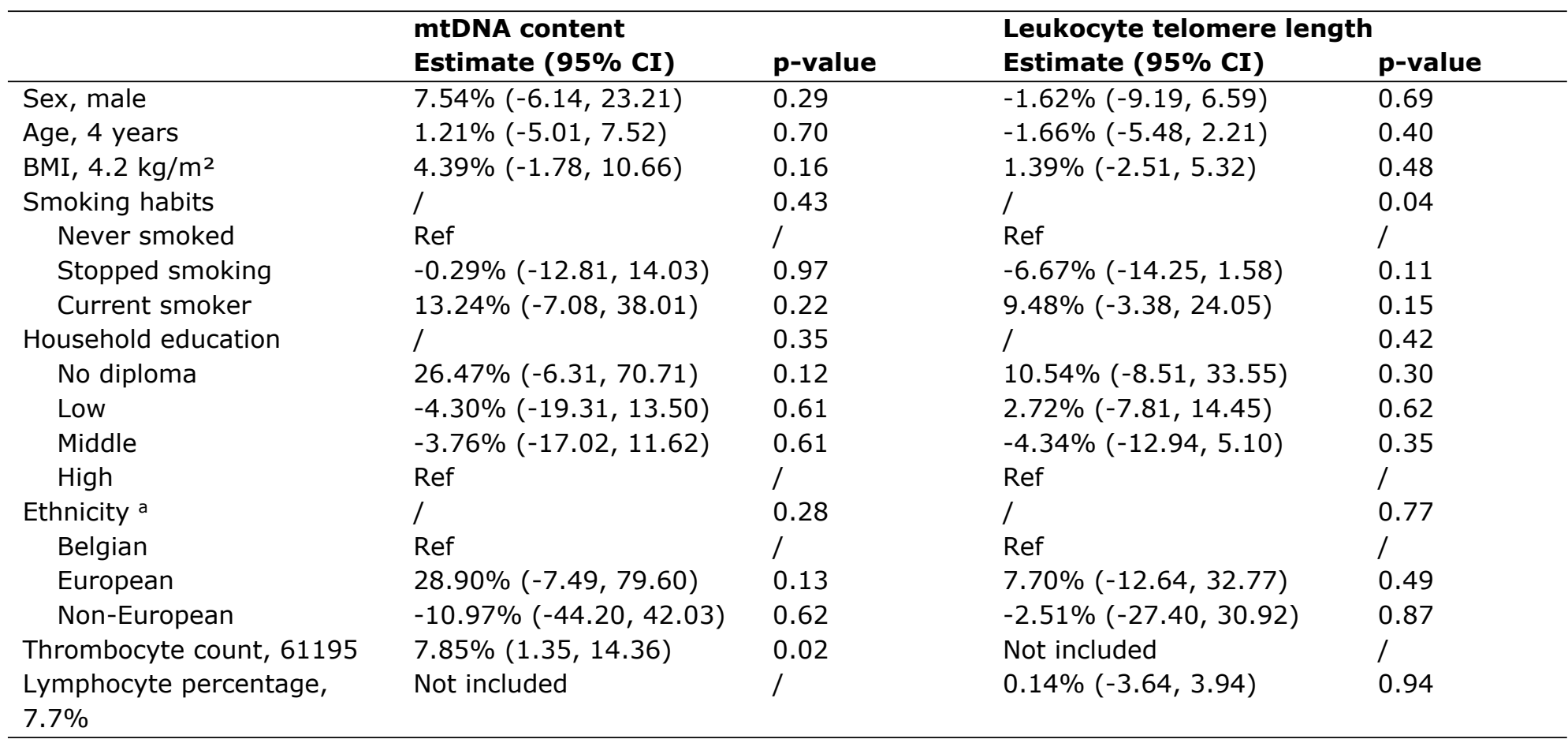

Effect estimates are presented as the relative change (\%) with 95\% CI in mtDNA content or telomere length for a SD increase for continuous variables or compared to a reference group for categorical variables. Models were adjusted for age, sex, BMI, smoking habits, household education, ethnicity, storage time and qPCR plates. In the mtDNA content model, thrombocyte count was additionally included, and in the telomere model the percentage of lymphocytes was additionally included. a: based on the country of birth of the participants. 
Table S4: Single pollutant models evaluating the change in mtDNA content associated with the biomarkers of exposure

\begin{tabular}{|c|c|c|c|}
\hline Biomarker & Estimate (95\% CI) & p-value & $\begin{array}{c}\text { FDR adj. p- } \\
\text { value }\end{array}$ \\
\hline Sb & $0.60(-2.90,4.23)$ & 0.74 & 0.90 \\
\hline As & $-0.12(-2.39,2.20)$ & 0.92 & 0.94 \\
\hline Cd & $0.54(-4.15,5.46)$ & 0.82 & 0.91 \\
\hline $\mathrm{Cu}$ & $-5.46(-10.14,-0.54)$ & 0.03 & 0.24 \\
\hline $\mathbf{H g}$ & $1.47(-0.96,3.95)$ & 0.24 & 0.52 \\
\hline $\mathbf{N i}$ & $-2.14(-5.56,1.40)$ & 0.23 & 0.52 \\
\hline TI & $-1.63(-8.02,5.20)$ & 0.63 & 0.82 \\
\hline РСB-138 & $1.55(-2.81,6.11)$ & 0.49 & 0.70 \\
\hline РCB-153 & $2.04(-3.26,7.62)$ & 0.46 & 0.70 \\
\hline РCB-180 & $2.19(-3.65,8.38)$ & 0.47 & 0.70 \\
\hline НСВ & $2.95(0.08,5.91)$ & 0.04 & 0.24 \\
\hline B-HCH & $1.83(-2.04,5.86)$ & 0.36 & 0.65 \\
\hline oxc & $6.05(0.46,11.94)$ & 0.03 & 0.24 \\
\hline $\mathbf{C N}$ & $2.84(-1.17,7.01)$ & 0.17 & 0.52 \\
\hline TN & $5.50(-0.32,11.66)$ & 0.06 & 0.28 \\
\hline p,p'-DDE & $1.01(-1.96,4.07)$ & 0.51 & 0.70 \\
\hline p,p'-DDT & $1.27(-1.41,4.01)$ & 0.35 & 0.65 \\
\hline BDE-153 & $3.14(-1.67,8.19)$ & 0.20 & 0.52 \\
\hline PFHxS & $0.16(-3.71,4.18)$ & 0.94 & 0.94 \\
\hline PFNA & $4.21(-0.76,9.43)$ & 0.10 & 0.36 \\
\hline PFOA & $0.71(-4.26,5.94)$ & 0.78 & 0.91 \\
\hline PFOS & $6.62(2.08,11.36)$ & 0.004 & 0.09 \\
\hline
\end{tabular}

Models were adjusted for age, sex, BMI, smoking habits, household education, ethnicity, thrombocyte count, storage time and batch effects. The estimated change is presented as the relative percentage (\%) change in mtDNA content associated with a $50 \%$ increment in the mean concentrations in the biomarker of environmental exposure.

Abbreviations: $\mathrm{Sb}=$ antimony, $\mathrm{As}=$ arsenic, $\mathrm{Cd}=$ cadmium, $\mathrm{Cu}=$ copper, $\mathrm{Hg}=$ mercury, $\mathrm{Ni}=\mathrm{nickel}, \mathrm{Tl}=$ thallium, $\mathrm{PCB}=$ polychlorinated biphenyl, $\mathrm{HCB}=$ hexachlorobenzene, $\beta-\mathrm{HCH}=\beta$-hexachlorocyclohexane, $\mathrm{OXC}=$ oxychlordane, $\mathrm{CN}=$ cis-nonachlor, $\mathrm{TN}=$ trans-nonachlor, $\mathrm{p}, \mathrm{p}^{\prime}-\mathrm{DDE}=\mathrm{p}, \mathrm{p}^{\prime}-$ dichlorodiphenyldichloroethylene, $\mathrm{p}, \mathrm{p}^{\prime}-\mathrm{DDT}=\mathrm{p}, \mathrm{p}^{\prime}$-dichlorodiphenyltrichloroethane, $\mathrm{BDE}=$ brominated diphenyl ether, $\mathrm{PFH} \times \mathrm{S}=$ perfluorohexane sulfonic acid, PFNA= perfluorononanoic acid, $\mathrm{PFOA}=$ perfluorooctanoic acid, PFOS= perfluorooctane sulfonic acid. 
Table 55: Single pollutant models evaluating the change in leukocyte telomere length associated with the biomarkers of exposure

\begin{tabular}{llcc}
\hline Biomarker & Estimate $(\mathbf{9 5 \%} \mathbf{C I})$ & p-value & $\begin{array}{c}\text { FDR adj. p- } \\
\text { value }\end{array}$ \\
\hline Sb & $1.83(-0.37,4.08)$ & 0.10 & 0.65 \\
As & $1.06(-0.38,2.52)$ & 0.15 & 0.65 \\
Cd & $-0.21(-3.17,2.83)$ & 0.89 & 0.93 \\
Cu & $-2.41(-5.49,0.76)$ & 0.13 & 0.65 \\
Hg & $1.58(0.06,3.11)$ & 0.04 & 0.64 \\
Ni & $0.55(-1.68,2.82)$ & 0.63 & 0.87 \\
TI & $1.77(-2.37,6.09)$ & 0.41 & 0.86 \\
PCB-138 & $-0.82(-3.48,1.91)$ & 0.55 & 0.86 \\
PCB-153 & $-0.31(-3.53,3.01)$ & 0.85 & 0.93 \\
PCB-180 & $-1.00(-4.57,2.70)$ & 0.59 & 0.86 \\
HCB & $-0.74(-2.50,1.06)$ & 0.42 & 0.86 \\
B-HCH & $0.75(-1.68,3.24)$ & 0.55 & 0.86 \\
OXC & $-0.68(-4.00,2.76)$ & 0.69 & 0.90 \\
CN & $0.82(-1.67,2.01)$ & 0.52 & 0.86 \\
TN & $0.35(-3.14,3.98)$ & 0.84 & 0.93 \\
P,P'-DDE & $0.16(-1.67,2.01)$ & 0.87 & 0.93 \\
p,p'-DDT & $0.07(-1.61,1.77)$ & 0.94 & 0.94 \\
BDE-153 & $1.18(-1.78,4.24)$ & 0.44 & 0.86 \\
PFHXS & $-1.40(-3.79,1.05)$ & 0.26 & 0.81 \\
PFNA & $-1.84(-4.79,1.21)$ & 0.23 & 0.81 \\
PFOA & $-3.00(-6.01,0.11)$ & 0.06 & 0.64 \\
PFOS & $-0.97(-3.67,1.81)$ & 0.49 & 0.86 \\
\hline Mof & & & \\
\hline
\end{tabular}

Models were adjusted for age, sex, BMI, smoking habits, household education, ethnicity, storage time and batch effects. The estimated change is presented as the relative percentage (\%) change in leukocyte telomere length associated with a $50 \%$ increment in the mean concentrations in the biomarker of environmental exposure.

Abbreviations: $\mathrm{Sb}=$ antimony, $\mathrm{As}=$ arsenic, $\mathrm{Cd}=$ cadmium, $\mathrm{Cu}=$ copper, $\mathrm{Hg}=$ mercury, $\mathrm{Ni}=\mathrm{nickel}, \mathrm{Tl}=$ thallium, $\mathrm{PCB}=$ polychlorinated biphenyl, $\mathrm{HCB}=$ hexachlorobenzene, $\beta-\mathrm{HCH}=\beta$-hexachlorocyclohexane, $\mathrm{OXC}=\quad$ oxychlordane, $\mathrm{CN}=$ cis-nonachlor, $\mathrm{TN}=$ trans-nonachlor, $\mathrm{p}, \mathrm{p}^{\prime}-\mathrm{DDE}=$ dichlorodiphenyldichloroethylene, $\mathrm{p}, \mathrm{p}^{\prime}$-DDT = dichlorodiphenyltrichloroethane, $\mathrm{BDE}=$ brominated diphenyl ether, $\mathrm{PFH} \times \mathrm{S}=$ perfluorohexane sulfonic acid, PFNA= perfluorononanoic acid, $\mathrm{PFOA}=$ perfluorooctanoic acid, PFOS= perfluorooctane sulfonic acid. 
Table S6: Beta coefficients* of selected pollutants by multivariate sPLS for biomarkers of aging

\section{mtDNA content Telomere length}

PFOS $0.036 \quad-0.0056$

* calculation of $95 \%$ CI is not supported for multivariate sPLS models in the sPLS package, however, from single pollutant models we learned that PFOS was only significantly associated to mtDNA content and not to telomere length. 
Table S7: Sensitivity analysis for leukocyte telomere length, additionally taking into account lymphocyte percentages

\begin{tabular}{lllll}
\hline $\begin{array}{l}\text { Selected } \\
\text { exposure }\end{array}$ & SPLS & OLS & \\
\hline $\mathrm{Sb}$ & $0.018(0.001,0.036)$ & 0.04 & $2.70 \%(0.43,5.01)$ & 0.02 \\
$\mathrm{Cu}$ & $-0.018(-0.033,-0.002)$ & 0.02 & $-3.51 \%(-6.67,-0.25)$ & 0.04 \\
$\mathrm{Hg}$ & $0.019(0.003,0.033)$ & 0.01 & $1.91 \%(0.41,3.44)$ & 0.01 \\
$\mathrm{PFOA}$ & $-0.017(-0.032,-0.001)$ & 0.03 & $-3.65 \%(-6.63,-0.57)$ & 0.02
\end{tabular}

a: Estimates are presented as the raw coefficients obtained from sPLS regression analyses. b: Estimates are presented as the relative change (\%) in leukocyte telomere length for a $50 \%$ increase in the mean concentrations of the biomarker of exposure. Models are adjusted for age, sex, BMI, smoking habits, household education, ethnicity, lymphocyte percentage, storage time and qPCR plates. 
Total study population FLEHS III adults $n=209$

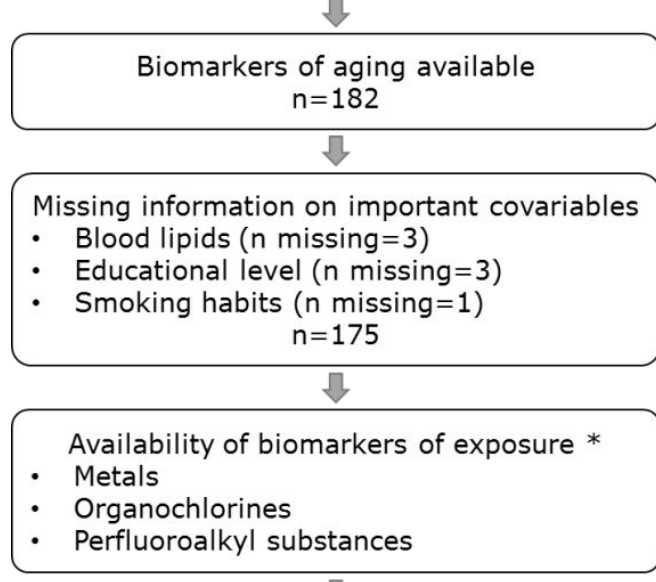

\section{Included in analyses: $\mathbf{n = 1 7 5}$}

* In the framework of HBM, other biomarkers of exposure were quantified as well, however, due to a high proportion of undetectable measurements $(>15 \%)$ or quantification in a subset of samples, they were not considered for the present study.

Figure S1: Flowchart illustrating the selection procedure of study participants from the FLEHS III cohort for the present study $(n=175)$. HBM= human biomonitoring 


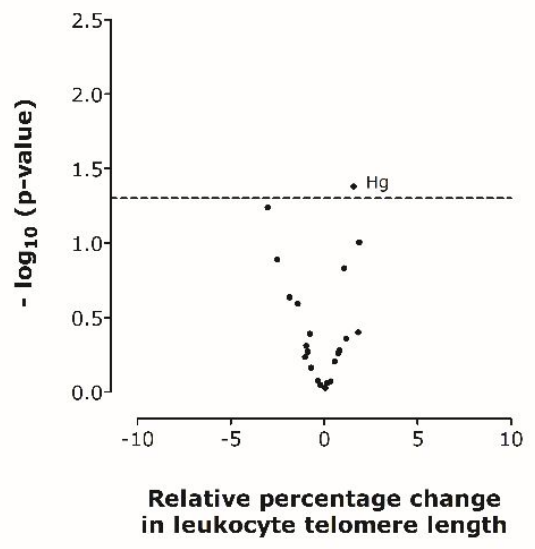

Figure S2: Volcano plot presenting the significance of the associations between biomarkers of environmental exposure and leukocyte telomere length (LTL) in function of the magnitude of the estimated change in LTL. Models were adjusted for age, sex, BMI, smoking habits, household education, ethnicity, storage time, batch effects and additionally for lymphocyte percentage. 

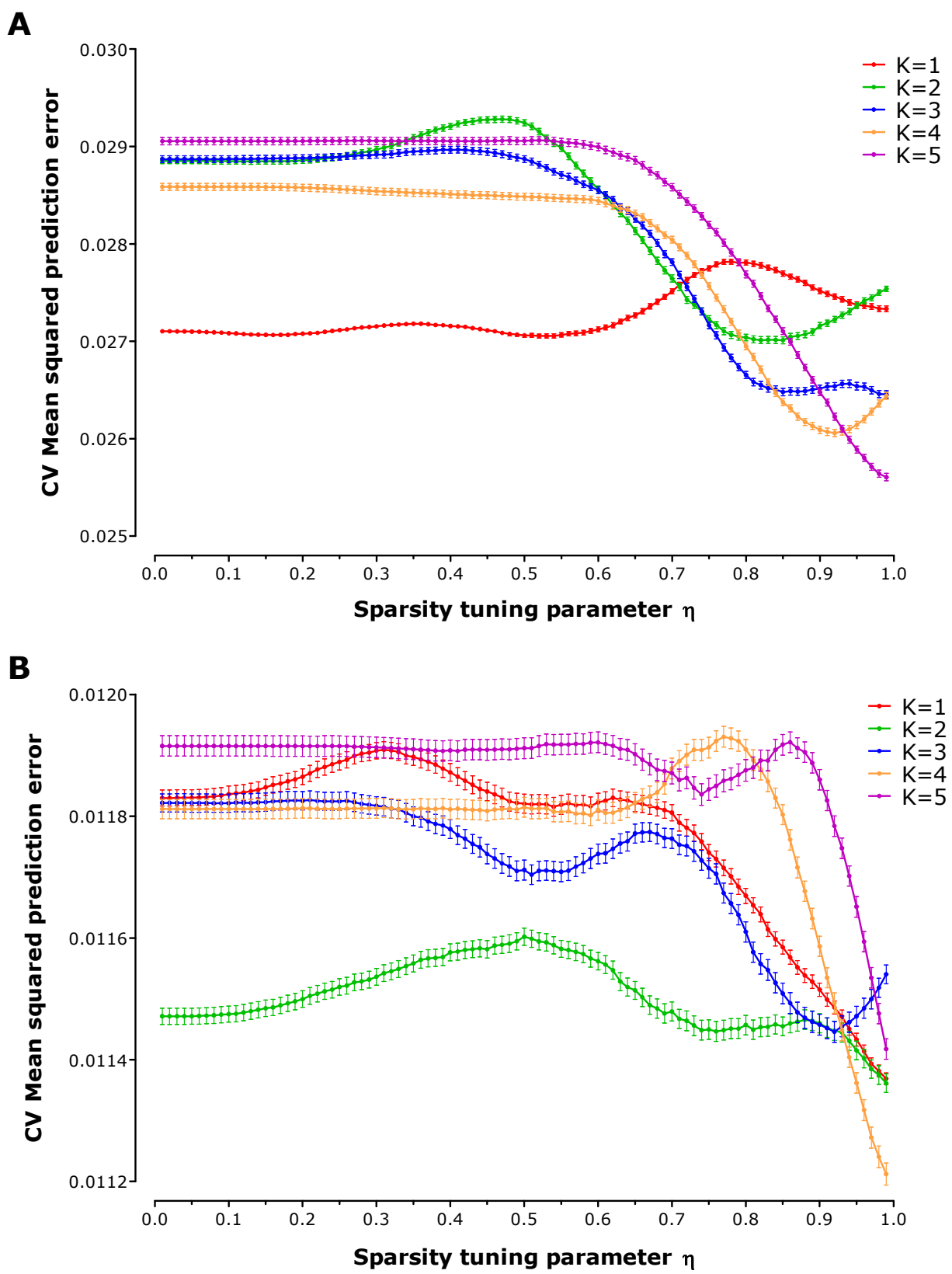

Figure S3: Error path for sPLS for mtDNA content determined by 500x 10-fold cross-validation, depicting the cross-validated mean squared prediction error (MSPE) with the standard errors in function of the sparsity tuning parameter $\eta$, for different numbers of components ranging from 1 to 5 . (A) error path for mtDNA content, with the optimal model $K=5$ components and very sparse with $\eta=0.99$; (B) error path for leukocyte telomere length with the optimal model $\mathrm{K}=4$ components and very sparse with $\eta=0.99$. 


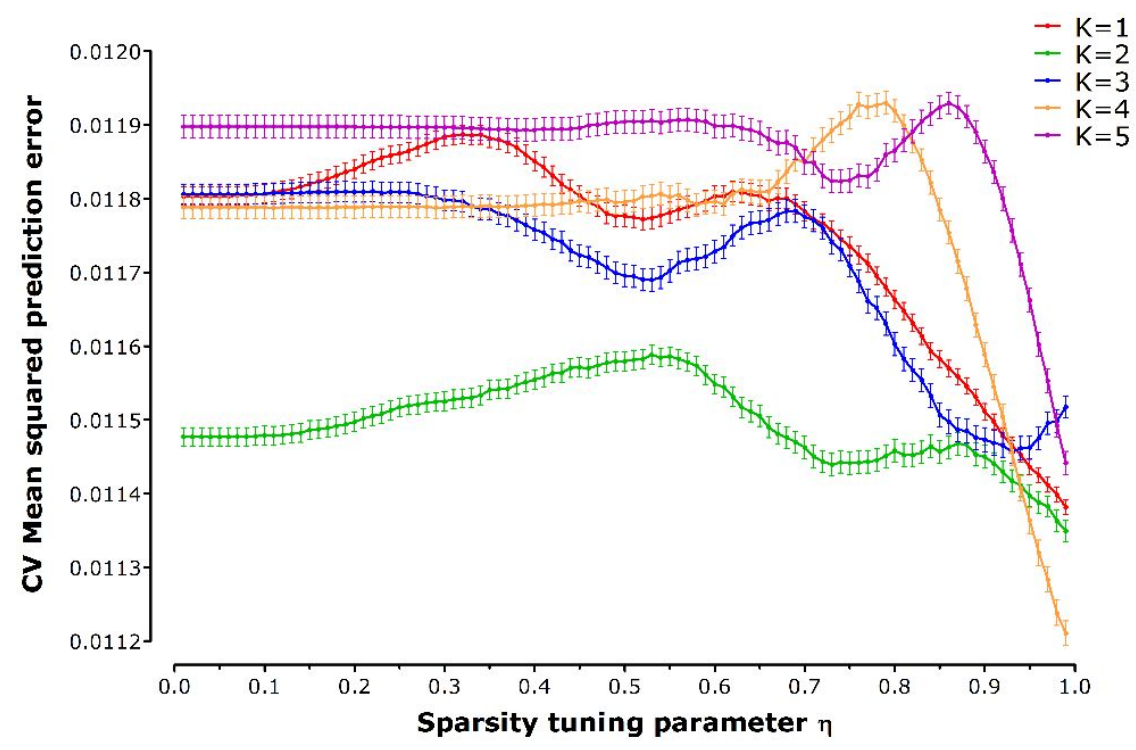

Figure S4: Error path for sPLS model for leukocyte telomere length, when additionally accounting for lymphocyte percentage, determined by 500x 10-fold cross-validation, depicting the cross-validated mean squared prediction error (MSPE) with the standard errors in function of the sparsity tuning parameter $\eta$, for different numbers of components ranging from 1 to 5 . The optimal model $K=4$ components and is very sparse with $\eta=0.99$. 


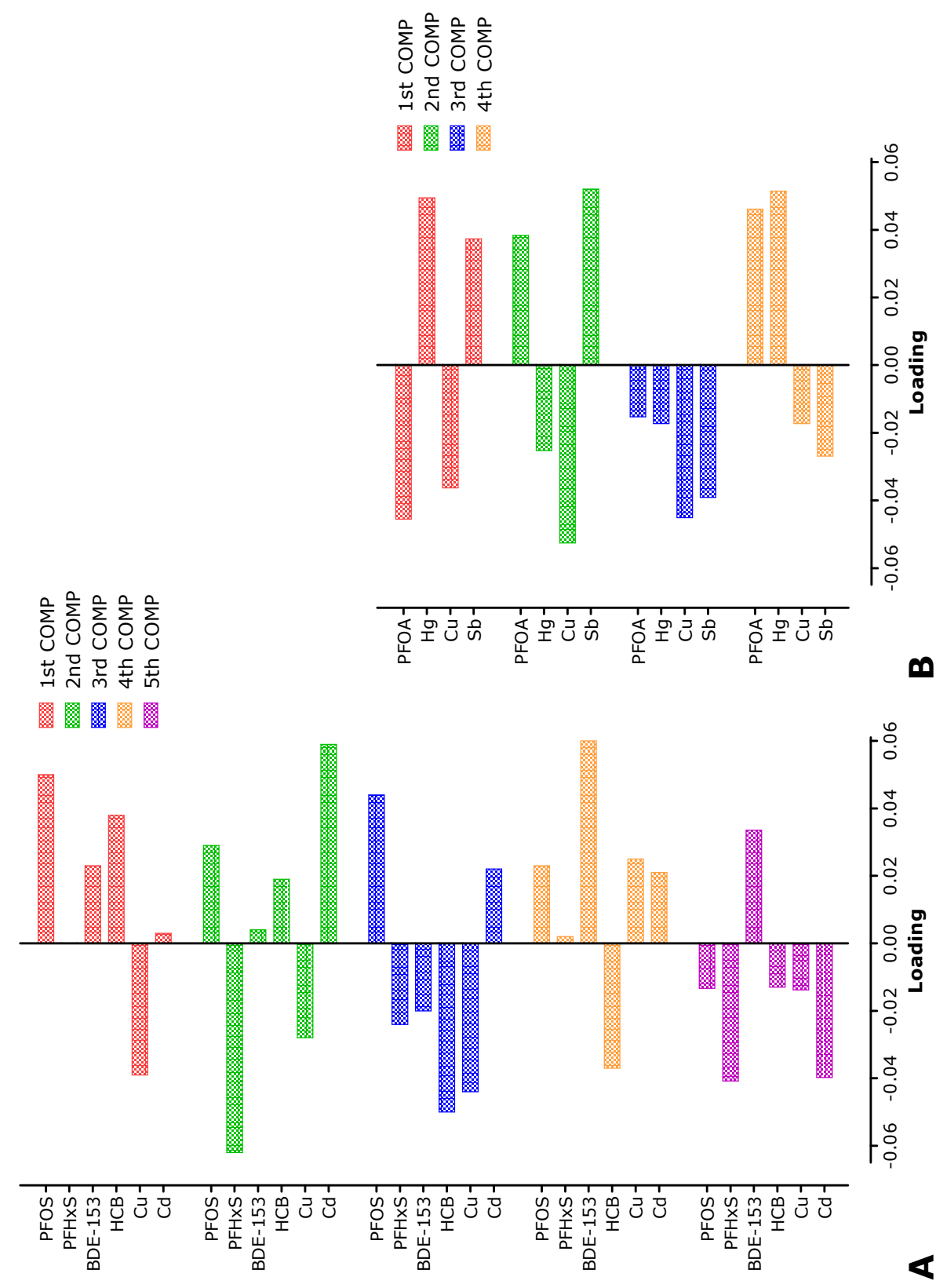

Figure S5: Loading of the selected biomarkers of exposure in the different components. (A) for sPLS regression model for mtDNA content, with six selected exposures and $\mathrm{K}=5$ components; (B) for sPLS regression model for telomere lenght, with four selected exposures and $\mathrm{K}=4$ components. 


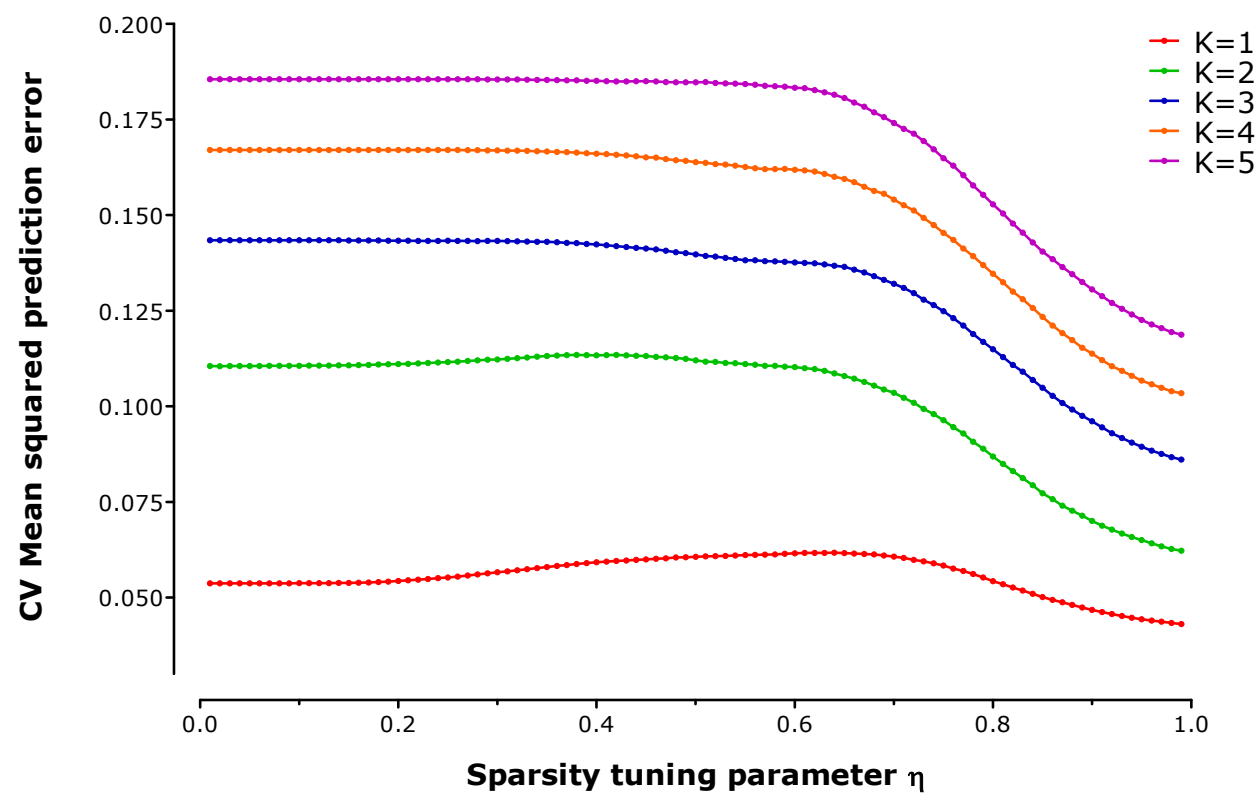

Figure S6: Error path for the multivariate sPLS model (including both mtDNA content and telomere length in the response matrix) determined by 500x 10 -fold cross-validation, depicting the cross-validated mean squared prediction error (MSPE) with the standard errors in function of the sparsity tuning parameter $\eta$, for different numbers of components ranging from 1 to 5 . The optimal model has $\mathrm{K}=1$ components and is very sparse with $\eta=0.99$. 